A N N A L E S

UNIVERSITATIS MARIAE CURIE-SKŁODOWSKA

LUBLIN - POLONIA

VOL. XXXI, 4

SECTIO J

2018

Uniwersytet Warszawski. Wydział Polonistyki

\title{
AGNIESZKA MIKOLAJCZUK
}

ORCID: 0000-0003-1830-0215

amikolajczuk@tlen.pl

\section{Konceptualizacja WSTYDU i DUMY utrwalona w polszczyźnie ogólnej i specjalistycznej (w języku psychologów) - na tle porównawczym języka angielskiego}

The Conceptualisation of SHAME/EMBARRASSMENT and PRIDE

in General Polish and Specialist Language (of Psychology) - in Comparison with English

\section{STRESZCZENIE}

Celem pracy jest porównanie potocznej i specjalistycznej językowej konceptualizacji przeżyć z kategorii WSTYDU i DUMY. Punkt wyjścia stanowi pytanie o rolę języka w kształtowaniu myśli i uczuć. Część główna obejmuje opis konceptualizacji wstydu i dumy utrwalonych w polszczyźnie ogólnej (w porównaniu z językiem angielskim) oraz analizę stosowanych przez psychologów i psychoterapeutów terminów i sposobów obrazowania tych przeżyć (w tekstach pisanych po polsku lub tłumaczonych z języka angielskiego na język polski). W zakończeniu wskazano na wartość interdyscyplinarnej współpracy między psychologami i lingwistami w zakresie badań nad emocjami.

Słowa kluczowe: lingwistyka kognitywna; językowa konceptualizacja uczuć; wstyd; duma

\section{WPROWADZENIE: ROLA JĘZYKA W KSZTAŁTOWANIU MYŚLI I UCZUĆ}

W niniejszym artykule spotykają się dwie dziedziny - lingwistyka i psychologia, przy czym analizy są prowadzone z perspektywy językoznawczej, polonistycznej. Celem jest spojrzenie na wybrane aspekty konceptualizacji uczuć przez pryzmat języka, który wykorzystujemy do mówienia (i myślenia) o przeżyciach psychicznych na co dzień oraz w sytuacjach angażujących wiedzę ekspercką. 
Chodzi zatem o sprawdzenie, jak zwykli ludzie i specjaliści (psychologowie i psychoterapeuci) kategoryzują i charakteryzują uczucia, a przykładem wybranym do analizy jest kategoria przeżyć samoświadomościowych.

L. Boroditsky, która bada porównawczo języki świata oraz ich związek ze sposobem rozumienia i codziennego operowania różnymi pojęciami przez użytkowników tych języków, dowodzi, że język w specyficzny dla siebie sposób kształtuje myślenie ludzi, którzy się nim posługują, zwłaszcza jeśli to myślenie dotyczy zjawisk słabo uchwytnych zmysłami (Boroditsky 2001, s. 20). Twierdzenie to wydaje się godne uwagi badaczy (języka) emocji, ponieważ uczucia nie są fenomenami bezpośrednio dostępnymi percepcji zewnętrznych obserwatorów ${ }^{1}$.

Zarówno laicy, jak i eksperci (w tym psychologowie i psychoterapeuci), chcąc poznać świat emocji, posiłkują się m.in. językiem jako narzędziem przekazu informacji o emocjach, ich porządkowania i wyrażania oraz organizowania badań nad nimi. Ze względu na to, że w danym języku (jego wyrażeniach: nazwach uczuć, kolokacjach i frazeologizmach, derywatach, kategoriach gramatycznych itp.) zapisany jest właściwy mu językowy obraz uczuć 2 , pojawia się pytanie, czy odpowiednio do możliwych różnic $w$ językowych obrazach emocji właściwych różnym językom etnicznym rozumienie i przeżywanie tych emocji przez użytkowników owych języków jest różne i czy tego rodzaju różnice ujawniają się też w pracach psychologów badających emocje, będących z jednej strony native speakerami określonych języków etnicznych, a z drugiej członkami wspólnoty naukowej, w której głównym językiem wymiany myśli stał się współcześnie język angielski (zob. Wierzbicka 1999a; Kurcz 2007; Brinkmann, Musaeus 2010, s. 134).

Tak jak lingwista koncentruje się na badaniu języka emocji, czyli rozumieniu nazw uczuć i relacji między pojęciami, które się z nimi wiążą w systemie danego języka i wypowiedziach jego użytkowników, czego efektem może być charakterystyka specyficznej dla tego języka kategoryzacji i konceptualizacji przeżyć psychicznych (zob. np. Kövecses 1986, 1998, 2003, 2011; Wierzbicka 1992, 1999a, 1999b; Nowakowska-Kempna 1995, 2000; Jędrzejko 2000; Pajdzińska 2004; Tissari 2006; Mikołajczuk 2009, 2012, 2014, 2016, 2017, w druku; Fabiszak, Hebda 2010; Saicová Ř́malová 2010), tak psycholog skupia się na analizie owych przeżyć i ich roli w życiu jednostki (zob. np. Ekman 1992a, 1992b, 1998, 2003; Lewis 2005, 2011, [b.d.w.]; Doliński 2011; Brzezińska 2017) i/lub sposobów ich rozumienia przez respondentów (zob. np. Harwas-Napierała, Trempała

1 O specyfice kategorii uczuć zob. np. prace R. Grzegorczykowej (2009, s. 2-24) oraz P. Wilsona i B. Lewandowskiej-Tomaszczyk (2010).

2 Termin ,językowy obraz świata” jest tu stosowany zgodnie z koncepcją J. Bartmińskiego (2006). 
1991, za: Danieluk 2013; Kleszczewska-Albińska, Albiński 2009; Jasielska 2010, 2012, 2013; Danieluk 2013; por. Kövecses 2003), traktując sam język jedynie jako narzędzie, a nie istotny obiekt badań. Mimo że wydaje się, iż przedstawiciele obu dyscyplin stoją po przeciwnych stronach, to zbliżać nas może, po pierwsze, dążenie do poznania rozumienia emocji, czyli sfery pojęciowej, a po drugie, fakt, że niezależnie od specjalizacji posługujemy się określonymi językami, planując i przeprowadzając badania oraz analizując ich wyniki i komunikując je innym. Warto zatem zapytać, czy ślad różnojęzycznych obrazów emocji jest możliwy do uchwycenia w pracach specjalistów i jakie to może mieć konsekwencje w praktyce (por. Saarni 2005, s. 400; Shweder, Haidt 2005, s. 520).

Uwzględniając powyższe pytania, skoncentrujemy się dalej na przykładach nazw uczuć z kategorii WSTYDU i DUMY, pochodzących z języka polskiego $i$ angielskiego. Zaczniemy od szkicowego przyjrzenia się danym z polszczyzny ogólnej (potwierdzonym w słownikach języka polskiego i Narodowym Korpusie Języka Polskiego [NKJP] oraz opracowaniach semantyków), by móc je odnieść do badań nad angielszczyzną oraz przykładów z wybranych prac psychologicznych.

\section{ROZUMIENIE WSTYDU I DUMY W POLSZCZYŹNIE OGÓLNEJ I W KONTEKŚCIE PORÓWNAWCZYM JĘZYKA ANGIELSKIEGO (SZKIC)}

Rozumienie wstydu. W polskojęzycznej konceptualizacji wstydu istotne są: rola podmiotu przeżyć (czyli kogoś, kto odczuwa lub może odczuwać wstyd - prototypowo jest to człowiek lub wspólnota ludzi), rola sprawcy tych przeżyć (czyli tego, kto powoduje powstanie uczucia - może nim być sam zdystansowany do siebie podmiot albo ktoś z nim związany ${ }^{3}$, ale też ktoś spoza wspólnoty, obserwowany przez podmiot) oraz role sędziego i publiczności (w roli sędziego może wystąpić sam podmiot lub zewnętrzny wobec niego świadek). Przeżycie wstydu może więc mieć charakter subiektywnego doznania indywidualnego, wspólnotowego lub zbiorowego (np. Byto mu wstyd za siebie / za syna; Konsternacja na widowni / na trybunach) albo zobiektywizowanego obligatywnego uczucia (np. Wstyd na to patrzeć! Wstydziłbyś się!). Podmiot wstydu nie musi mieć kontroli nad tym przeżyciem, nieraz nawet jakby dobrowolnie się mu poddaje (np. Wstyd go ogarnąt; Wstyd mi vs. Wstydze się - zob. Wierzbicka 1999b, s. 178). Uczucie to ma swoją przyczynę - może nią być czyjaś przegrana (np. wstyd porażki) lub cechy świadczące zdaniem podmiotu i/lub publiczności o niskiej jego wartości, słabości (np. Wstydził się swego pochodzenia / tuszy), ale też sytuacje, w których

3 Można wówczas mówić o podmiocie „rozszerzonym”, zależnym od innych osób (należących do tej samej wspólnoty). O takiej konstrukcji ,ja”, włączającej bliskich, przyjaciół i większe grupy, typowej dla kultur kolektywistycznych, piszą m.in. A. Ogarkova, C. Soriano i C. Lehr (2010, s. 262, 263), porównując różne nazwy uczuć w wybranych językach europejskich. 
to, co jest zastrzeżone dla sfery intymnej czy prywatnej, zostaje upublicznione (np. wstydliwe tematy; Wstydziła się rozebrać). Do typowych objawów wstydu należą: czerwienienie się i odczuwanie gorąca (np. Zrobit się czerwony jak burak. Palit go wstyd) oraz wycofywanie się, np. unikanie kontaktu wzrokowego i chęć ukrycia się, ucieczki lub nieistnienia (np. Nie wiedział, gdzie oczy podziać. Chciatby zapaść się pod ziemię), a także zahamowanie i dezorganizacja działań (np. Paraliżowat go wstyd. Milczat zawstydzony). Siła tego przeżycia jest stopniowalna: od bardzo dużej do niewielkiej (np. wielki wstyd, odrobina wstydu), przy czym podmiot może niekiedy wysiłkiem woli zapanować nad swoim wstydem i zrobić coś wbrew temu, co czuje (np. Przezwyciężyt wstyd). To m.in. pokazuje, że sama emocja jest przez podmiot odczuwana jako coś złego, nieprzyjemnego, utrudniającego normalne funkcjonowanie. Wyrażająca dezaprobatę fraza Wstydu nie ma! dowodzi jednak, że brak (umiejętności) przeżywania wstydu w pewnych sytuacjach jest oceniany negatywnie, zatem poczucie wstydu, zniechęcające podmiot do złego postępowania, jawi się jako coś pożądanego, pozytywnego, zwłaszcza w oczach zewnętrznych obserwatorów (por. reprymendy typu: Wstyd! Wstydziłbyś się!) (zob. Zaron 2006; Mikołajczuk 2012, 2017).

A. Wierzbicka i H. Tissari wskazują, że taka regulacyjna funkcja wstydu, powiązana m.in. z kontekstem religijnym, podobnie jak jego wspólnotowy, a nie tylko indywidualistyczny charakter, były dawniej (do początku XX w.) wpisane również $\mathrm{w}$ angielskie pojęcie opisywane słowem shame, w którego rozumieniu współcześnie dominującą rolę odgrywa model indywidualistyczny i sekularny (zob. Wierzbicka 1999a, s. 108-121; Tissari 2006, s. 152). Jako przeżycie bardzo silne, niepoddające się kontroli i destrukcyjne dla podmiotu (zob. metafory zniszczenia: Kövecses 1986, 1998) emocja shame jest oceniana bardzo negatywnie (zob. Hurtado-de-Mendoza, Molina, Fernández-Dols 2012). W porównaniu z parą przeżyć traktowanych w polszczyźnie jako rozłączne: wstydu i poczucia winy, emocja opisywana przez angielski shame zdaniem badaczy ściślej łączy się z poczuciem winy (guilt) i żalem (regret) (zob. Tissari 2006, s. 150; Lewandowska-Tomaszczyk, Wilson 2014)4, a więc z ogólną kategorią SMUTKU. Wskazują na to także typowe objawy i metaforycznie skonceptualizowane skutki shame (widoczne np. w obrazowaniu przez fizyczne uszkodzenie, pomniejszenie i niepełny obiekt: Kövecses 1998; zob. Mikołajczuk 2012, s. 141-142). Tymczasem uczucie określane w angielszczyźnie jako embarrassment jawi się jako w dużej mierze odrębne od wstydu/shame, bo wymagające audytorium (zob. Krawczak 2017) i bliżej powiązane z kategorią ogólną STRACHU (zob. Lewandowska-Tomasz-

4 Zauważmy, że niektórzy psychologowie, świadomi różnic kulturowych, dowodzą również większej zbieżności między wstydem (shame) i poczuciem winy (guilt) w świadomości respondentów amerykańskich w porównaniu z polskimi respondentami (zob. np. Kleszczewska-Albińska, Albiński 2009, s. 94). 
czyk, Wilson 2014; Krawczak 2017). O wyraźnej rozłączności shame i embarrassment oraz o specyficznym miejscu wstydu mogą świadczyć też przywołane przez B. Lewandowską-Tomaszczyk i P. Wilsona (2014, s. 142) wyniki analizy korpusów równoległych obejmujących tłumaczenia tekstów polskich i angielskich: shame i wstyd zyskują w nich ekwiwalenty thumaczeniowe odsyłające do rozbieżnych kategorii pojęciowych: a) shame $\rightarrow$ wstyd, upokorzenie, niesława, hańba, zniewaga; b) wstyd $\rightarrow$ embarrassment, bashfulness, timidity, annoyance itd.

Zatem polski wstyd (podobnie jak jego odpowiedniki w wielu innych niż angielski językach, np. hiszpańskim czy holenderskim) (zob. Scheff 2003; Hurtado-de-Mendoza i in. 2012; Osch, Breugelmans, Zeelenberg 2013) obejmuje swym zakresem to, co angielszczyzna rozdziela między kategorie SHAME i EMBARRASSMENT, a nawet SHYNESS (zob. Mikołajczuk 2012, 2014).

Rozumienie dumy. W utrwalone w polszczyźnie pojęcie DUMY wpisuje się pozytywna samoocena podmiotu przeżyć. Sprawcą dumy (podobnie jak wstydu) nie musi być jednak sam podmiot, lecz - w ramach rozszerzonego ,ja” - także ktoś z nim związany (choć już nie ktoś zupełnie niezależny od podmiotu występującego w roli świadka) (np. Byt dumny z siebie / z syna). Typową przyczyną dumy jest sukces (np. Sukces napawat go duma), ale też różne cechy wartościowane przez podmiot pozytywnie, postrzegane jako zalety (np. Jestem dumny, że jestem Polakiem; Byt dumny ze swego pochodzenia / ze swojej sity) oraz wyjątkowe czyny, które według zewnętrznego sędziego dają ich wykonawcy powód do dumy (np. chwalebne i bohaterskie czyny, chwalebna działalność na rzecz kraju itp.). Samo przeżycie jest ujmowane jako niepodlegające kontroli podmiotu, ale zachowania i działania podmiotu wyrażające to uczucie (np. chwalenie się, afiszowanie się z czymś itp.) jawią się jako chętnie przezeń podejmowane (np. Pysznit się wta$d z a$; Dumnie paradowat na koniu). Typowymi objawami dumy są: wyprostowana sylwetka, wypięta pierś, głowa uniesiona wysoko (np. Duma/pycha go rozpiera; Chodzi z podniesiona glowa), co daje podstawę metaftonimicznym określeniom człowieka (zbyt) dumnego, pysznego, zarozumiałego (np. Zadziera nosa; Patrzy na innych z góry; Wynosi się nad innych.). Siła przeżycia dumy może być zróżnicowana: od bardzo dużej do niewielkiej (np. wielka duma, odrobina dumy), ale w odniesieniu do pychy postrzeganej jako cecha charakteru podmiotu mówimy tylko o bardzo intensywnym przeżyciu $\mathrm{i}$ - w przeciwieństwie do dumy uzasadnionej - wartościowanym wyłącznie negatywnie (por. grzech pychy). Źródło tego wartościowania pychy jest prototypowo zewnętrzne wobec podmiotu. Pyszny wariant dumy, czyli postawa egoistycznego eksponowania siebie i pogardy dla innych, jest uznawany za szkodliwy dla samego podmiotu (zaburza bowiem jego postrzeganie rzeczywistości i jest moralnie zły, np. Zaślepia go pycha) oraz dla wspólnoty (zaburza relacje z innymi), dlatego taka duma może być celowo ograniczana (np. Ukrócili jego pychę). Poza dumą pyszną (przeciwstawianą pokorze, skromności) można mówić w polszczyźnie o co najmniej dwóch równie ważnych 
modelach dumy: dumie reaktywnej (przeciwstawianej wstydowi) oraz dumie godnościowej (przeciwstawianej poczuciu niższości i upokorzenia) (zob. Mikołajczuk 2016, w druku; por. Grzegorczykowa, Piotrowska 2011; Grzegorczykowa 2012).

Z badań nad językiem angielskim i porównań z polszczyzną wynika, że ogólne obrazy dumy i pride są zasadniczo podobne, choć Z. Kövecses mocno podkreśla indywidualistyczny, a nie wspólnotowy model dumy jako prototypowy dla współczesnego języka angielskiego (Kövecses 1986, s. 44-49), a za jeden z jej typowych objawów uznaje czerwienienie się (Kövecses 1986, s. 40, 48), M. Fabiszak i A. Hebda (2010) z kolei pokazują, że ocena negatywna włączyła się w wartościowanie dumy/pride w języku angielskim dopiero pod wpływem chrześcijaństwa, dlatego m.in. to pride pojawia się na liście siedmiu grzechów głównych w języku angielskim. Co ważne, rzeczownik pride obejmuje pozytywne i negatywne warianty przeżyć w rodzaju dumy, przy braku w języku ogólnym jednego określenia na oznaczenie wariantu negatywnego (odpowiednika polskiej pychy) (zob. Kövecses 1986; por. Saicová Římalová 2010; Mortillaro, Ricci-Bitti, Bellelli, Galati 2013; Osch, Breugelmans, Zeelenberg, Fontaine 2013).

Świadectwa stosowania w polszczyźnie wstydu i dumy w odniesieniu do kategorii ogólnych, nadrzędnych znajdujemy m.in. we współczesnych wypowiedziach i słownikach ${ }^{5}$. Dla przykładu w nagłówku cyklu tekstów prasowych na temat wstydu, opublikowanych w „Wysokich Obcasach Extra” w 2014 r., czytamy: „Wiele pięter wstydu: nieśmiałość, zażenowanie, speszenie, lęk przed wystąpieniami, otyłość, bieda, poczucie winy [podkr. - A.M.], przyzwoitość, destrukcja" (Szostak 2014, s. 26-27).

W zakresie kategorii ogólnej WSTYDU umieszczono tu jako podkategorie zarówno 'nieśmiałość', 'speszenie' i 'lęk przed wystąpieniami', jak i 'zażenowanie’ oraz 'poczucie winy’ i związaną z nim 'przyzwoitość' (a także wskazujące na typowe przyczyny wstydu 'otyłość' i 'biedę' oraz uogólnione konsekwencje wstydu w postaci 'destrukcji'). Widać tu połączenie kategorii ogólnej WSTYDU z kategoriami STRACHU i SMUTKU, czego potwierdzenie znajdujemy w definicjach słownikowych haseł z omawianego pola (zob. ISJP 2000; USJP 2003; WSJP 2007) oraz w opracowaniach semantycznych (zob. Jędrzejko 2000; Zaron 2006; Mikołajczuk 2012, 2017).

Jeśli chodzi o dumę, to np. w poniższym wpisie internetowym rzeczownik duma jawi się jako nazwa kategorii ogólnej oraz określenie kategorii bardziej szczegółowych: ,dumy pomocnej”, opartej na uznaniu przez podmiot swoich zalet i zadowoleniu, a więc ocenianej pozytywnie, i „dumy pysznej” - egoistycznej, nietolerancyjnej, wyłączającej podmiot ze wspólnoty i ocenianej zdecydowanie negatywnie:

5 Niekiedy również w pracach psychologów (zob. np. Brzezińska 2017, s. 164). 
W moim odczuciu duma posiada dwie strony jest du ma ktora pomaga mi podniesc swoja wlasna wartosc (bo z tym mam jeszcze nieraz klopoty) i w tedy moge skupic sie na swoich zaletach ktore sa wlasnie powodem do dumy dla mnie. Jednak gdy przekrocze niewidzialna linie gdzie moje prozne ego bierze gore juz ta duma nie jest spojnym elementem gdzie jest miejsce na zrozumienie akceptacje zadowolenie tylko wlancza sie pycha arogancja brak tolerancji to wszystko laczy sie w jedna prozna pyszna uzalajaca sie dume [podkr.-A.M.]. To tylko ode mnie zalezy ktora strone wybiorę (zapis oryginalny, http://niepijemy.pl/forum/10-forum-alkoholowe/81414-duma-a-pycha).

Widać tu pośrednie odesłania do innych kategorii ogólnych: RADOŚCI i SMUTKU oraz POGARDY. Związek DUMY z RADOŚCIĄ, a zwłaszcza PYCHY z POGARDĄ jest zaświadczony też w opisach leksykograficznych (zob. np. ISJP 2000) oraz w studiach semantycznych (por. Mikołajczuk 2009, 2016) ${ }^{6}$, przy czym niektórzy badacze akcentują mocniej powiązanie DUMY z kategorią SZACUNKU (zob. zwłaszcza: Goździk 2001; Grzegorczykowa 2012).

Omówione przykłady pokazują, że w potocznej kategoryzacji uczuć różne nazwy przeżyć nie muszą układać się w system opisujący płaską taksonomię, lecz dzięki wieloznaczności czy wariancji znaczeń oraz relacjom semantycznym tworzą bardziej złożone układy. W języku polskim i języku angielskim układy te, jak widać, nie są identyczne, gdyż zakresy poszczególnych kategorii ogólnych i szczegółowych nie w pełni się w nich pokrywają, a pojęcia z różnych poziomów mogą (choć nie zawsze tak jest) mieć w nich odrębne (i równie mocno eksploatowane w tekstach) nazwy.

Jak sobie z tym radzi psychologia? M. Lewis, uznawany za jednego z głównych badaczy emocji samoświadomościowych w psychologii rozwojowej, dostrzega problemy $\mathrm{z}$ wielością kategorii emocji mieszczących się $\mathrm{w}$ zakresie angielskiego rzeczownika pride, uznając jego wieloznaczność za przeszkodę w pogłębieniu analizy badanych przeżyć i tłumacząc tym słabe zainteresowanie psychologów dumą/pride (Lewis 2005, s. 789). Co ciekawe, podobnych zastrzeżeń ten sam autor nie ma wobec shame, co w kontekście polskojęzycznym może zastanawiać. $Z$ uwagi na to, że na jego model emocji samoświadomościowych powołuje się wielu autorów, nie tylko psychologów i psychoterapeutów anglo- czy innojęzycznych, w tym polskojęzycznych (np. Lewis, Haviland-Johnes 2005; Łosiak 2007; Jasielska 2010; Doliński 2011), ale także anglistów (np. Tissari 2006; Hurtado-de-Mendoza i in. 2012), jego propozycjom przyjrzymy się dokładniej w dalszej części tekstu. Analizie zostanie poddany materiał językowy zaczerpnięty $\mathrm{z}$ prac tego autora (opublikowanych $\mathrm{w}$ oryginale po angielsku i w thumaczeniu na polski) oraz z wybranych poradników psychologicznych odnoszących się do przeżyć z ogólnej kategorii WSTYDU, wydanych po polsku jako teksty oryginalne lub thumaczenia $\mathrm{z}$ angielskiego.

\footnotetext{
6 Także w tekstach psychologicznych (por. Jasielska 2010, 2013).
} 


\section{NAZYWANIE I ROZUMIENIE PRZEŻYĆ SAMOŚWIADOMOŚCIOWYCH W DYSKURSIE PSYCHOLOGICZNYM - ANALIZA JĘZYKOZNAWCZA}

Lewis, prezentując psychologiczny model emocji samoświadomościowych, posłużył się kilkoma leksemami zaczerpniętymi z angielszczyzny ogólnej lub książkowej. Zostały one uwzględnione, wraz z określeniami polskimi, potraktowanymi przez tłumaczy jako ich ekwiwalenty w przekładzie na język polski, w tab. 1 .

Tab. 1. Terminy zastosowane przez M. Lewisa i polskich tłumaczy jego tekstów w typologii przeżyć samoświadomościowych

\begin{tabular}{|c|c|c|c|c|c|}
\hline \multicolumn{3}{|c|}{$\begin{array}{c}\text { Lewis ([b.d.w.], 2011) } \\
\text { (oryginał w języku angielskim) }\end{array}$} & \multicolumn{3}{|c|}{$\begin{array}{c}\text { Lewis (2005) } \\
\text { (tłumaczenie na język polski) }\end{array}$} \\
\hline 1. & \multicolumn{2}{|c|}{ Shame } & 1. & \multicolumn{2}{|c|}{ Wstyd } \\
\hline 2. & \multicolumn{2}{|c|}{ Guilt or regret } & 2. & \multicolumn{2}{|c|}{ Poczucie winy lub żalu } \\
\hline & \multicolumn{2}{|c|}{ Embarrassment } & & \multicolumn{2}{|c|}{ Zażenowanie } \\
\hline 3. & $\begin{array}{l}\text { embarrassment } \\
\text { from exposure }\end{array}$ & $\begin{array}{c}\text { evaluative } \\
\text { embarrassment } \\
=\text { less intense shame }\end{array}$ & 3. & $\begin{array}{c}\text { zażenowanie } \\
\text { zwiazane } \\
\text { z ekspozycja }\end{array}$ & $\begin{array}{c}\text { zażenowanie zwiazane } \\
\text { z samoocena }=\text { mniej } \\
\text { intensywny wstyd }\end{array}$ \\
\hline 4. & \multicolumn{2}{|c|}{$\begin{array}{l}\text { Shyness w: (Lewis [b.d.w.]; brak w: } \\
\text { (Lewis 2011) }\end{array}$} & 4. & \multicolumn{2}{|c|}{ Onieśmielenie (nieśmiałość) } \\
\hline \multirow{2}{*}{5.} & \multicolumn{2}{|c|}{ Pride } & \multirow{2}{*}{5.} & \multicolumn{2}{|c|}{ Duma } \\
\hline & Pride & Hubris & & Duma & Pycha \\
\hline
\end{tabular}

Rozstrzelonym drukiem zaznaczono terminy, które określają główne składniki modelu przeżyć samoświadomościowych w typologii M. Lewisa (por. 2005, s. 785, rycina 39.1.)

Źródło: opracowanie własne.

Zebrany w tab. 1 materiał leksykalny budzi w polskim czytelniku kilka wątpliwości, chociaż w świetle anglistycznych charakterystyk nie powinien zaskakiwać odbiorcy anglojęzycznego. Do takich nieoczywistych dla użytkowników polszczyzny rozwiązań należą:

1. Zgodne $z$ anglojęzycznym myśleniem usytuowanie obok siebie wstydu/ shame i poczucia winy/guilt jako emocji bliskich sobie, związanych z uświadomieniem sobie przez podmiot jego porażki. W rozumieniu poczucia winy w polszczyźnie profilowane są jednak nie porażki, lecz zrobienie komuś czegoś złego i oparta na tym relacja między krzywdzącym a skrzywdzonym (Falkowska 2012, s. 69; por. Kleszczewska-Albińska, Albiński 2009; Lewandowska-Tomaszczyk, Wilson 2014; Krawczak 2015).

2. Uznanie wstydu/shame za przeżycie prywatne, niewymagające audytorium, niekoniecznie publiczne (w przeciwieństwie do zażenowania/embarrassment, które wiąże się obligatoryjnie $\mathrm{z}$ wystawieniem podmiotu na 
widok publiczny) oraz mocne rozdzielenie tych przeżyć (choć z zaznaczeniem rozwarstwienia embarrassment na dwa warianty - jeden bliższy onieśmieleniu, a drugi reprezentujący słabszy wstyd). Jak pokazuje B. Danieluk (2013), polskojęzyczni respondenci zarówno we wstydzie, jak i w zakłopotaniu ${ }^{7}$ widzą zaangażowanie samoświadomości publicznej, a nie prywatnej.

3. Pominięcie aspektu wspólnotowego (,ja” rozszerzone vs. ,ja” niezależne) w charakterystyce poszczególnych przeżyć ${ }^{8}$.

4. Potraktowanie wstydu/shame jako przeżycia dużo silniejszego niż poczucie winy/guilt i bardziej od niego destrukcyjnego (Lewis 2005, s. 788). W badaniach polskich respondentów psycholodzy stwierdzili odwrotną sytuację - poczucie winy jawi się Polakom jako silniejsze niż wstyd (Harwas-Napierała, Trempała 1991, za: Danieluk 2013).

5. Brak czerwienienia się i odczucia gorąca na liście typowych objawów wstydu/shame wymienionych przez Lewisa (i jednocześnie uznanie czerwienienia się za wyznacznik wstydu w rozumieniu jego prototypu m.in. u polskich respondentów badanych przez A. Jasielską [2012]) (por. Kleszczewska-Albińska, Albiński 2009, s. 90).

6. Niejasny status nieśmiałości/onieśmielenia/shyness w modelu Lewisa - nie zawsze są w tym modelu uwzględniane, uznaje się je za niezwiązane z samooceną, za to ściśle łączą się z ogólną kategorią STRACHU. Dodatkowo w thumaczeniu polskim potraktowanie terminów onieśmielenie i nieśmiatość jako równoznacznych, mających odniesienie do tej samej klasy przeżyć (bez uwzględnienia zróżnicowania na emocję krótkotrwałą, reaktywną oraz stałą cechę osobowości), pozostaje w niezgodzie z wzorcem językowym polszczyzny (zob. np. Bednarek 2004; Mikołajczuk 2014).

Nieoczywiste z punktu widzenia czytelnika anglojęzycznego może natomiast być wyodrębnienie kategorii pychy/hubris obok dumy/pride, ponieważ słowo hubris jest we współczesnej angielszczyźnie używane bardzo rzadko, jest wyraźnie nacechowane stylistycznie (ograniczone do tekstów oficjalnych; zob. LDCE 1989)9

7 Embarrassment bywa thumaczone jako zażenowanie (Lewis 2005) i zaktopotanie (Miller 2000; Danieluk 2013).

8 Jak jednak pokazują badania A. Jasielskiej (2010) czy A. Kleszczewskiej-Albińskiej i R. Albińskiego (2009, s. 7), część psychologów, biorąc pod uwagę różnice międzykulturowe, uwzględnia ten aspekt w analizie emocji samoświadomościowych.

9 Definicje słownikowe pokazują ponadto, że w rozumieniu hubris i pychy inaczej są rozłożone akcenty: negatywna ocena postawy podmiotu wypływa w rozumieniu hubris z przewidywania bardzo złych konsekwencji dla samego podmiotu (hubris 'great and unreasonable pride, often bringing great misfortune to the person who shows it' - LDCE 1989, s. 511), a w rozumieniu pychy - z destrukcyjnego działania na relacje z innymi (pycha 'wygórowane mniemanie o sobie, będące 
i może być odbierane jako termin specjalistyczny - takiego efektu w polskim thumaczeniu nie $\mathrm{ma}^{10}$.

Pojawia się zatem pytanie, na ile kategoryzacja przeżyć, oparta w dużej mierze (ale nie w pełni) na podpowiadanych przez język angielski leksykalnych rozróżnieniach, może się przyjąć w szerszym gronie badaczy i niespecjalistów. Zdaniem Kövecsesa im większa zgodność teorii emocji z ich potocznym rozumieniem, tym większa popularność tej teorii wśród ekspertów i laików (Kövecses 2003, s. 126). Problem powstaje wtedy, gdy dana teoria, stworzona pod wpływem jednego języka (w tym przypadku angielskiego), jest przenoszona na grunt innojęzyczny.

Poleganie na podpowiedziach jednego z języków może mieć konsekwencje znaczące dla samych badań, czego dowód widzimy w przykładzie dotyczącym przeżyć związanych z nieśmiałością/shyness, które w modelu Lewisa zdają się odgrywać marginalną rolę. B. Carducci w książce zatytułowanej Shyness. A Bold New Approach (1999), a w polskim tłumaczeniu Nieśmiatość. Nowe odważne podejście (2008), napisał m.in.: „Scientists have been studying shy cattle as well as shy cats, shy fish, and shy dogs" (Carducci 1999, s. 3), co przełożono na: „Jak dotąd naukowcy badali też nieśmiałe krowy, koty, ryby oraz nieśmiałe psy" (Carducci 2008, s. 15). Przywołane tłumaczenie pokazuje, że autor rozszerzył zakres swoich badań, kierując się nie tylko tym znaczeniem angielskiego przymiotnika shy, w którym słowo to opisuje przeżycia oraz cechy osobowości człowieka ('onieśmielony, nieśmiały'), ale też znaczeniem mającym odniesienie do zwierząt, kiedy opisywane są charakterystyczne zachowania: 'płochliwy' (zob. np. definicje shy w LDCE 1989). Dlatego przytoczony tu fragment brzmi po angielsku najprawdopodobniej naturalnie, ale dla polskiego czytelnika stanowi wyzwanie - po polsku w neutralnych, pozabaśniowych kontekstach nie mówimy o nieśmiałych rybach czy krowach. Pojawia się więc pytanie, co tak naprawdę było przedmiotem badań autora: określona kategoria cech emocjonalnych człowieka (nieśmiałość) czy ogólniejsza kategoria skłonności do obserwowalnych u ludzi i zwierząt zachowań (płochliwość).

często powodem pogardliwego stosunku do innych' - ISJP 2000 II, s. 402). Osobiste szczęście w kontekście angielskim, a udane relacje społeczne w kontekście polskim stanowią różne wartości, zagrożone przez hubris i pychę, zatem oczekiwania polsko- i anglojęzycznych czytelników wpisane w rozróżnienia zaproponowane przez Lewisa i tłumaczy jego tekstów też mogą być różne.

10 Również inni psycholodzy są zgodni w wyodrębnianiu co najmniej dwóch różnych rodzajów dumy/pride, a określają je jako authentic pride i hubristic pride (Tracy, Robins 2007; Tracy, Weidman, Cheng, Martens 2014; Shi i in. 2015). P. Ekman (2003) natomiast nie wydziela tych dwóch typów, lecz - wykorzystując argumenty lingwistyczne - wskazuje na istnienie obok dumy/ pride i triumfu/triumph, mających swoje nazwy w języku angielskim (i nie tylko), także inne rodzaje dumy, wyróżniane leksykalnie jedynie przez niektóre nacje: dumy z osiągnięć bez rywalizacji (fiero w języku włoskim) oraz dumy rodziców z dzieci (naches w jidysz). 
Inny problem - akceptowalności i skuteczności przekazu - można rozważyć, analizując metaforyczne obrazowanie kategorii WSTYDU w poradnikach psychologicznych, czyli w publikacjach tworzonych zazwyczaj przez specjalistów z myślą o udzieleniu wsparcia osobom nieradzącym sobie z emocjami ${ }^{11}$. Przeprowadzona przeze mnie analiza dotyczy dwóch poradników, wybranych jako przykład do dokładniejszej obserwacji. Są to: przetłumaczony z języka angielskiego na język polski tom pt. Toksyczny wstyd. Jak uzdrowić wstyd, który cię zniewala autorstwa angloamerykańskiego psychoterapeuty J. Bradshawa (1997) oraz napisana po polsku książka Wstyd. Jak lepiej go rozumieć i nie pozwolić, żeby zatruwat nam życie autorstwa polskiej psychoterapeutki A. Dodziuk (1999) (notabene wielokrotnie powołuje się ona na pracę Bradshawa).

Porównanie wybranych (podobnych pod względem objętości i funkcji) partii obu tekstów w ich polskojęzycznych wydaniach (rozdziałów początkowych i końcowych) oraz zestawienie z danymi NKJP (próbką tysiąca przykładów użyć słowa wstyd wybraną losowo z tego korpusu) pozwala stwierdzić, że autorzy wielokrotnie częściej niż twórcy tekstów zgromadzonych w korpusie polszczyzny ogólnej odwołują się do domen: WALKI i PRZECIWNIKA (Bradshaw dwu-, a Dodziuk czterokrotnie częściej), CHOROBY i BÓLU (Bradshaw piętnasto-, a Dodziuk ośmiokrotnie częściej) oraz TRUCIZNY (Bradshaw stu-, a Dodziuk dwudziestopięciokrotnie częściej). Dzięki takiemu obrazowaniu wstyd jest w badanych poradnikach ukazywany jako uczucie ekstremalnie niebezpieczne, wymagające podjęcia zdecydowanych działań naprawczych, co zgadza się z charakterystyką wstydu/shame zaproponowaną przez Lewisa, a także z przeznaczeniem tego typu publikacji (pomaganie w sytuacjach trudnych). Co równie istotne, w książce Bradshawa zabrakło, a w pracy Dodziuk ujawniło się wprawdzie, ale trzykrotnie słabiej niż w NKJP, obrazowanie wstydu przez odniesienie do domeny OGNIA i GORĄCA. Takie obrazowanie w próbce z NKJP jawi się jako najbardziej użyteczne, najczęstsze - określenia typu: kogoś pali/piecze wstyd, ktoś by się ze wstydu spalit, ktoś płonie wstydem itp. służą w języku polskim do mówienia o uczuciu bardzo intensywnym, ale zarazem wyraźnie się objawiającym i przez to dającym się rozpoznać. Nie jest to obraz, który by pasował do wizerunku wstydu uwewnętrznionego, tabuizowanego, często nawet nieuświadamianego przez jednostkę, jak go opisują badacze z kręgu anglosaskiego (Scheff 2003; Lewis 2005; por. Danieluk 2013). Brak omawianego obrazowania w tekście Bradshawa, przetłumaczonym z języka angielskiego, wydaje się naturalnym odbiciem sposobu

11 O roli metaforycznego obrazowania w przekazach naukowych i popularnonaukowych pisze m.in. M. Zawisławska (2011), wskazując nie tylko na przydatność metafor w tworzeniu i przyswajaniu (funkcja poznawcza), wyjaśnianiu (funkcja egzegetyczna) i nazywaniu (funkcja katachretyczna) nowych obiektów i dziedzin, ale też ostrzegając przed niebezpieczeństwem zafałszowań wnoszonych przez metafory do rozumienia teorii i faktów. 
myślenia podpowiadanego przez język oryginału, a nie język docelowy. Natomiast widoczne wprawdzie, choć stosunkowo słabe (w porównaniu z tekstami reprezentującymi polszczyznę ogólną), potwierdzenie takiego obrazowania w poradniku polskiej autorki można tłumaczyć dopasowaniem sposobu myślenia do przyzwyczajeń i oczekiwań użytkownika polszczyzny. Na ile to wystarczy, by zdobyć zaufanie adresatów książki i skłonić ich do podążania tropem myśli i rad psychoterapeutki, to można ocenić dopiero po przeprowadzeniu badań wymagających współpracy interdyscyplinarnej.

\section{ZAKOŃCZENIE}

Zaprezentowane przykłady i wnioski płynące z ich analizy można potraktować jako argumenty potwierdzające istotną rolę języka w badaniu emocji i ich rozumienia. Język służy nie tylko wyrażaniu emocji i komunikowaniu o nich, jest również narzędziem ich porządkowania i interpretowania, a nawet modyfikowania, ale może też stanowić zaporę $\mathrm{w}$ ich rozpoznawaniu i rozumieniu. Im lepiej poznamy niuanse językowej konceptualizacji uczuć, zapisanej w różnych językach etnicznych i różnych rodzajach dyskursów (np. psychologicznym i psychoterapeutycznym), tym bardziej skuteczne kroki można będzie podjąć w usuwaniu blokad i tworzeniu warunków sprzyjających terapii, edukacji i wszechstronnemu rozwojowi jednostek i społeczeństw. Do tego potrzebna jest współpraca interdyscyplinarna, szerokie, „wielooczne" spojrzenie może bowiem prowadzić do pogłębionego rozumienia.

W tym kontekście ważne wydaje się pytanie zadane przez Kövecsesa dotyczące potrzeby, możliwości czy konieczności wyzwalania się badaczy z potocznych teorii emocji zapisanych w językach, którymi się posługują (Kövecses 2003, s. 114). Nawet jeśli uznamy, że nie musimy lub nie jesteśmy w stanie w pełni odrzucić właściwego naszym językom sposobu postrzegania przeżyć, to z pewnością powinniśmy mieć świadomość jego istnienia oraz uwarunkowań, jakie na nas nakłada - chociażby po to, by ostrożniej podchodzić do własnych intuicji i proponować rozwiązania (teoretyczne, psychoterapeutyczne, edukacyjne, prorozwojowe) najlepsze w dokładnie rozpoznanym kontekście (językowym, społecznym, historycznym, kulturowym). Aby to osiągnąć, warto podjąć interdyscyplinarną współpracę.

\section{BIBLIOGRAFIA}

Bańko, M. (red.). (ISJP). (2000). Inny słownik języka polskiego (2 T.). Warszawa: PWN.

Bartmiński, J. (2006). Punkt widzenia, perspektywa, językowy obraz świata. W: Językowe podstawy obrazu świata (s. 76-88). Lublin: Wydawnictwo UMCS.

Bednarek, A. (2004). Z pewnym zażenowaniem o onieśmieleniu... Próba analizy semantycznej. W: A. Moroz, M. Wiśniewski (red.), Studia z gramatyki i semantyki języka polskiego (s. 251-259). Toruń: Wydawnictwo UMK. 
Boroditsky, L. (2001). Does Language Shape Thougt? Mandarin and English Speakers' Conceptions of Time. Cognitive Psychology, 43(1), 1-22. DOI: https://doi.org/10.1006/cogp.2001.0748.

Bradshaw, J. (1997). Toksyczny wstyd. Jak uzdrowić wstyd, który cię zniewala. Warszawa: Akuracik. Brinkmann, S., Musaeus, P. (2010). Emotions and the Moral Order. W: P.A. Wilson (ed.), Dynamicity in Emotion Concepts (s. 123-137). Frankfurt am Main: Peter Lang.

Brzezińska, A.I. (2017). Gotowość do spotkania z innym: tożsamość u progu dorosłości. W: J.M. Brzeziński (red.), Obcy i swoi. Psychologiczna natura stosunków międzyludzkich (s. 133-211). Poznań: Wydawnictwo Naukowe Wydziału Nauk Społecznych UAM.

Carducci, B.J. (1999). Shyness. A Bold New Approach. New York: Harper Collins Publishers.

Carducci, B.J. (2008). Nieśmiałość. Nowe odważne podejście. Kraków: Wydawnictwo Znak.

Danieluk, B. (2013). Ile jest Ja w emocjach samoświadomościowych? Rodzaj zaangażowania Ja a wstyd, poczucie winy i zakłopotanie. Psychologia Społeczna, 83(26), 302-322.

Dodziuk, A. (1999). Wstyd. Jak lepiej go rozumieć i nie pozwolić, żeby zatruwat nam życie. Warszawa: Instytut Psychologii Zdrowia, Polskie Towarzystwo Psychologiczne.

Doliński, D. (2011). Wstyd-perspektywa psychologiczna. Pobrane z: www.e-znaczenia.pl/?p=746.

Dubisz, S. (red.). (USJP). (2003). Uniwersalny słownik języka polskiego (4 T.). Warszawa: PWN.

Ekman, P. (1992a). An Argument for Basic Emotions. Cognition and Emotion, 6(3-4), 169-200. DOI: https://doi.org/10.1080/02699939208411068.

Ekman, P. (1992b). Are There Basic Emotions? Psychological Review, 99(3), 550-553.

DOI: https://doi.org/10.1037/0033-295X.99.3.550.

Ekman, P. (1998). Wszystkie emocje są podstawowe. W: P. Ekman, R.J. Davidson (red.), Natura emocji: podstawowe zagadnienia (s. 20-25). Gdańsk: GWP.

Ekman, P. (2003). Sixteen Enjoyable Emotions. Emotion Researcher, 18, 6-7.

Fabiszak, M., Hebda, A. (2010). Cognitive historical approaches to emotions: Pride. W: M.E. Winters, H. Tissari, K. Allan (eds.), Historical Cognitive Linguistics (s. 261-297). Berlin-New York: De Gruyter Muton.

Falkowska, M. (2012). Semantyka winy we wspótczesnej polszczyźnie. Warszawa: Wydział Polonistyki UW.

Goździk, M. (2001). O dumie. Analiza semantyczna. Acta Universitatis Nicolai Copernici. Filologia Polska, 50(347), 61-76.

Grzegorczykowa, R. (2009). Punkty dyskusyjne w rozumieniu pojęcia językowego obrazu świata widziane z perspektywy badań porównawczych. Etnolingwistyka, 21, 15-29.

Grzegorczykowa, R. (2012). Nazwy pokory, pychy i pojęć pokrewnych. W: Świat widziany poprzez słowa. Szkice z semantyki leksykalnej (s. 92-106). Warszawa: Wydawnictwa UW.

Grzegorczykowa, R., Piotrowska, A.E. (2011). Świat jest teatrem niekończących się zmagań o ludzką godność. Kształtowanie się pojęcia godności w dziejach polszczyzny. W: A. Janowska, M. Pastuchowa, R. Pawelec (red.), Humanizm w języku polskim. Wartości humanistyczne w polskiej leksyce i refleksji o języku (s. 79-148). Warszawa: Neriton.

http://niepijemy.pl/forum/10-forum-alkoholowe/81414-duma-a-pycha (dostęp: 10.04.2018).

Hurtado-de-Mendoza, A., Molina, C., Fernández-Dols, J.-M. (2012). The Archeology of Emotion Concepts: A Lexicographic Analysis of the Concepts Shame and Vergüenza. Journal of Language and Social Psychology, 32(3), 272-290. DOI: https://doi.org/10.1177/0261927X12465610. 
Jasielska, A. (2010). Analiza narracji jako źródła wiedzy o emocjach. Prezentacja metody. W: M. Straś-Romanowska, B. Bartosz, M. Żurko (red.), Badania narracyjne w psychologii (s. 203-224). Warszawa: Eneteia.

Jasielska, A. (2012). Treść i struktura prototypu wstydu jako przykładu emocji złożonej. Roczniki Psychologiczne, 15(3), 101-107.

Jasielska, A. (2013). Charakterystyka i konsekwencje potocznego rozumienia emocji. Poznań: Wydawnictwo UAM.

Jędrzejko, E. (2000). O językowych wykładnikach pojęcia WSTYD w różnych koncepcjach opisu. W: I. Nowakowska-Kempna, A. Dąbrowska, J. Anusiewicz (red.), Uczucia w języku i tekście (s. 59-77). Wrocław: Wydawnictwo Uniwersytetu Wrocławskiego.

Kleszczewska-Albińska, A., Albiński, R. (2009). Wstyd i poczucie winy w teorii i badaniach. Psychologia Jakości Życia, 8(1), 83-100.

Kövecses, Z. (1986). Metaphors of Anger, Pride, and Love. A Lexical Approach to the Structure of Concepts. Amsterdam: John Benjamins.

Kövecses, Z. (1998). Are there any emotion-specific metaphors? W: A. Athanasiadou, E. Tabakowska (eds.), Speaking of Emotions. Conceptualisation and Expression (s. 127-151). BerlinNew York: Mouton de Gruyter.

Kövecses, Z. (2003). Metaphor and Emotion. Language, Culture, and Body in Human Feeling. Cambridge-Paris: Cambridge University Press and Maison des Sciences de l'Homme.

Kövecses, Z. (2011). Język, umyst, kultura. Praktyczne wprowadzenie. Kraków: Universitas.

Krawczak, K. (2015). Negative self-evaluative emotions from a cross-cultural perspective. A case of 'shame' and 'guilt' in English and Polish. Pobrane z: http://www.lattice.cnrs.fr/IMG/pdf/ Karolina_Krawczak_Negative_self-evaluative_emotions_Accepted.pdf.

Krawczak, K. (2017). Contrasting languages and cultures. A multifactorial profile-based account of SHAME in English, Polish, and French. Pobrane z: https://halshs.archives-ouvertes.fr/ halshs-01464866.

Kurcz, I. (2007). A może w miejsce dwujęzyczności - język globalny? W: I. Kurcz (red.), Psychologiczne aspekty dwujęzyczności (s. 457-465). Gdańsk: GWP.

LDCE (1989). Longman Dictionary of Contemporary English. London: Longman Group UK.

Lewandowska-Tomaszczyk, B., Wilson, P. (2014). Self-Conscious Emotions in Collectivistic and Individualistic Cultures: A Contrastive Linguistic Perspective. W: J. Romero-Trillo (ed.), Yearbook of Corpus Linguistics and Pragmatics. 2: New Empirical and Theoretical Paradigms (s. 123-148). Switzerland: Springer International Publishing.

Lewis, M. (2005). Emocje samoświadomościowe: zażenowanie, duma, wstyd, poczucie winy. W: M. Lewis, J.M. Haviland-Jones (red.), Psychologia emocji (s. 780-797). Gdańsk: GWP.

Lewis, M. (2011). The self-conscious emotions. Pobrane z: www.child-encyclopedia.com/emotions/ according-experts/self-conscious-emotions.

Lewis, M. (b.d.). Self-Conscious Emotions - Shame and guilt, Hubris and pride, Shyness and embarrassment. Pobrane z: http://psychology.jrank.org/pages/564/Self-Conscious-Emotions.html.

Lewis, M., Haviland-Jones, J.M. (red.). (2005). Psychologia emocji. Gdańsk: GWP.

Łosiak, W. (2007). Psychologia emocji. Warszawa: Wydawnictwa Akademickie i Profesjonalne. 
Mikołajczuk, A. (2009). Obraz radości we współczesnej polszczyźnie. Warszawa: Semper.

Mikołajczuk, A. (2012). Konceptualizacja wstydu w polszczyźnie (na tle porównawczym). W: A. Mikołajczuk, K. Waszakowa (red.), Odkrywanie znaczeń w języku (s. 124-145). Warszawa: Wydawnictwa Uniwersytetu Warszawskiego.

Mikołajczuk, A. (2014). O nieśmiałości (i wstydliwości) w języku polskim (ujęcie semantyczne). Prace Filologiczne, 64(2), 251-274.

Mikołajczuk, A. (2016). Czy duma to przeżycie odświętne? Z badań nad konceptualizacją dumy (ang. pride) w polszczyźnie. W: L. Saicová Římalová, I. Vaňková (red.), Lidský život a každodennost v jazyce (s. 105-119). Praha: Univerzita Karlova, Filozofická fakulta.

Mikołajczuk, A. (2017). Między słowami a przeżyciami: O rozumieniu wstydu we współczesnym języku polskim. Ethos. Kwartalnik Instytutu Jana Pawła II KUL, 118 (kwiecień-czerwiec), 101-126.

Mikołajczuk, A. (w druku). Complex Concept of DUMA ('PRIDE') in Polish - from a Lexicographic Approach to Discourse Analysis. W: M. Grygiel, R. Kiełtyka (eds.), Cognitive Linguistics in the Year 2017. Rzeszów.

Miller, R. (2000). Niepewność i zakłopotanie. O pokonywaniu niechcianych uczuć. Gdańsk: GWP.

Mortillaro, M., Ricci-Bitti, P.E., Bellelli, G., Galati, D. (2013). Pride is not created equal: Variations between Northern and Southern Italy. W: J.J.R. Fontaine, K.R. Scherer, C. Soriano (eds.), Components of Emotional Meanings. A Sourcebook (s. 366-376). Oxford: Oxford University Press.

Narodowy Korpus Języka Polskiego (NKJP). Wyszukiwarka PELCRA. www.nkjp.pl.

Nowakowska-Kempna, I. (1995). Konceptualizacja uczuć w języku polskim. Prolegomena. Warszawa: Sorus.

Nowakowska-Kempna, I. (2000). Konceptualizacja uczuć w języku polskim (Cz. 2: Data). Warszawa: WSP TWP.

Ogarkova, A., Soriano, C., Lehr, C. (2010). Naming Feeling: Exploring the Equivalence of Emotion Terms in Five European Languages. W: P.A. Wilson (ed.), Dynamicity in Emotion Concepts (s. 253-284). Frankfurt am Main: Peter Lang.

Osch, Y.M.J., Breugelmans, S.M., Zeelenberg, M. (2013). The meaning of Dutch "schaamte" as a single term for shame and embarrassment. W: J.J.R. Fontaine, K.R. Scherer, C. Soriano (eds.), Components of Emotional Meanings. A Sourcebook (s. 486-489). Oxford: Oxford University Press.

Osch, Y.M.J., Breugelmans, S.M., Zeelenberg, M., Fontaine J.J.R. (2013). The meaning of pride across cultures. W: J.J.R. Fontaine, K.R. Scherer, C. Soriano (eds.), Components of Emotional Meanings. A Sourcebook (s. 377-387). Oxford: Oxford University Press.

Pajdzińska, A. (2004). Jak mówimy o uczuciach? Poprzez analizę frazeologizmów do językowego obrazu świata. W: J. Bartmiński (red.), Językowy obraz świata (s. 83-101). Lublin: Wydawnictwo UMCS.

Saarni, C. (2005). Społeczny kontekst rozwoju emocjonalnego. W: M. Lewis, J.M. Haviland-Jones (red.), Psychologia emocji (s. 392-412). Gdańsk: GWP.

Saicová Ř́malová, L. (2010). Pỳcha v českém jazykovém obraze světa. W: I. Vaňková, J. Pacovská (red.), Obraz člověka v jazyce (s. 144-154). Praha: Univerzita Karlova v Praze, Filozofická fakulta, Ústav českého jazyka a teorie komunikace. 
Scheff, T.J. (2003). Shame in Self and Society. Symbolic Interaction, 26(2), 239-262.

DOI: https://doi.org/10.1525/si.2003.26.2.239.

Shi, Y., Chung, J.M., Cheng, J.T., Tracy, J.L., Robins, R.W., Chen, X., Zheng, Y. (2015). Cross-Cultural Evidence for the Two-Facet Structure of Pride. Journal of Research in Personality, 55, 61-74. DOI: https://doi.org/10.1016/j.jrp.2015.01.004.

Shweder, R.A., Haidt, J. (2005). Psychologia kulturowa emocji - od starożytności po czasy współczesne. W: M. Lewis, J.M. Haviland-Jones (red.), Psychologia emocji (s. 504-524). Gdańsk: GWP.

Szostak, V. (2014). Wiele pięter wstydu. Wysokie Obcasy Extra, 7(28), wrzesień, 26-37.

Tissari, H. (2006). Conceptualizing Shame: Investigating Uses of the English Word Shame, 14181991. W: R.W. McConchie, O. Timofeeva, H. Tissari, T. Säily, Selected Proceedings of the 2005 Symposium on New Approaches in English Historical Lexis (HEL-LEX). Somerville: Cascadilla Proceedings Project.

Tracy, J.L., Robins, R.W. (2007). The Psychological Structure of Pride: A Tale of Two Facets. Journal of Personality and Social Psychology, 92(3), 506-525.

DOI: https://doi.org/10.1037/0022-3514.92.3.506.

Tracy, J.L., Weidman, A.C., Cheng, J.T., Martens, J.P. (2014). Pride: The Fundamental Emotion of Success, Power, and Status. W: M.M. Tugade, M.N. Shiota, L.D. Kirby (eds.), Handbook of Positive Emotions (s. 294-310). New York: Guilford Press.

Wierzbicka, A. (1992). Shame, Embarrassment, and Fear. W: Semantics, Culture, and Cognition: Universal Human Concepts in Culture-Specific Configurations (s. 130-134). New YorkOxford: Oxford University Press.

Wierzbicka, A. (1999a). Defining emotion concepts: discovering cognitive scenarios. W: Emotions Accross Languages and Cultures: Diversity and Universals (s. 49-122). Cambrigde: Cambridge University Press.

Wierzbicka, A. (1999b). Język-umyst - kultura. Warszawa: PWN.

Wilson, P.A., Lewandowska-Tomaszczyk, B. (2010). The Nature of Emotions. W: P.A. Wilson (ed.), Dynamicity in Emotion Concepts (s. 13-36). Frankfurt am Main: Peter Lang.

Zaron, Z. (2006). Wstyd ostatnia niecnoty zapora. O pojęciu wstydu. W: H. Karaś (red.), Czynić stowami. Studia ofiarowane Krystynie Dlugosz-Kurczabowej (s. 392-399). Warszawa: Wydział Polonistyki UW.

Zawisławska, M. (2011). Metafora w języku nauki. Na przykładzie nauk przyrodniczych. Warszawa: Wydział Polonistyki UW.

Żmigrodzki, P. (red.). (WSJP). (2007-). Wielki słownik języka polskiego. Pobrane z: http://wsjp.pl. 


\section{SUMMARY}

The aim of the paper is to compare the common and specialist linguistic conceptualization of emotions such as wstyd/shame/embarrassment and duma/pride. The point of departure is the question: What role do languages play in forming thoughts and feelings? In the main part, we describe how wstyd/shame/embarrassment and duma/pride are understood in general Polish (compared to English) and analyze the terms and ways used by psychologists and psychotherapists to portray these emotions in their works (in texts written in Polish or translated into Polish from English). In conclusion, the paper emphasizes the value of interdisciplinary cooperation between psychologists and linguists as regards research into emotions.

Keywords: cognitive linguistics; linguistic conceptualization of emotions; shame; embarrassment; pride 